\title{
A New Methodology for Estimating the Output Gap in the United States
}




\section{WP/15/144}

\section{IMF Working Paper}

\section{A New Methodology for Estimating the Output Gap in the United States}

by Ali Alichi

IMF Working Papers describe research in progress by the author(s) and are published to elicit comments and to encourage debate. The views expressed in IMF Working Papers are those of the author(s) and do not necessarily represent the views of the IMF, its Executive Board, or IMF management.
I N
N T E R

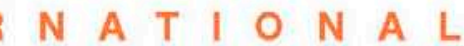
$M O N E T A R Y$
F U N D 


\title{
IMF Working Paper
}

Western Hemisphere Department

\section{A New Methodology for Estimating the Output Gap in the United States Prepared by Ali Alichi}

Authorized for distribution by Nigel Chalk

July 2015

IMF Working Papers describe research in progress by the author(s) and are published to elicit comments and to encourage debate. The views expressed in IMF Working Papers are those of the author(s) and do not necessarily represent the views of the IMF, its Executive Board, or IMF management.

\begin{abstract}
The gap between potential and actual output - the output gap - is a key variable for policymaking. This paper adapts the methodology developed in Blagrave and others (2015) to estimate the path of output gap in the U.S. economy. The results show that the output gap has considerably shrunk since the Great Recession, but still remains negative. While the results are more robust than other existing methodologies, there is still significant uncertainty surrounding the estimates.
\end{abstract}

JEL Classification Numbers: C51, E31, E52

Keywords: Macroeconomic Modeling, Potential Output, Output Gap

Author's E-Mail Address: aalichi@imf.org 


\section{Contents}

I. Introduction __ $\underline{3}$

II. Definitions __ 4

III. Existing Methodologies ___ 4

IV. Methodology__

V. Results __ 11

VI. Dealing with the End-of-Sample Problem ___ 12

VII. Conclusion___ 13

References ___ 14

Appendix I: Estimation Results ___ $\underline{16}$

Appendix II: Labor Force Participation Projections ___ 16 


\section{INTRODUCTION}

The U.S. real GDP growth slowed significantly during the Great Recession (GR). This was also reflected in very high unemployment and very low capacity utilization rates. Growth has since improved, but some argue that the recovery has not been strong enough to close the large economic slack that the GR caused. In fact, core inflation has been persistently below the U.S. Fed's 2.0 percent objective, providing support that, more than five years after the GR, there is still slack in the economy. As such, monetary policy has remained very accommodating to support the recovery. An important question for policymakers is how large the size of the remaining slack currently is. The answer to this question is becoming more important as the time for the normalization of monetary policy is approaching.

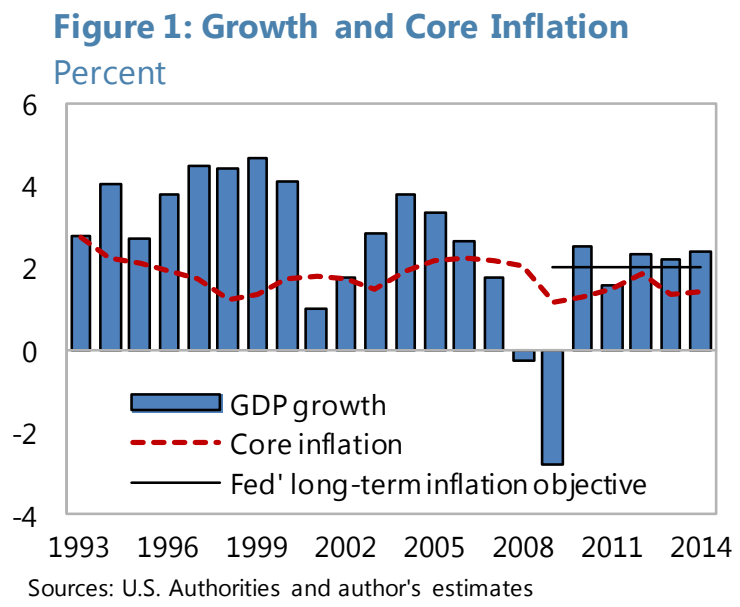

This paper is a new attempt, among many in the profession, to measure the size of the slack in the U.S. economy. We adapt the methodology developed by Blagrave and others $(2015)^{1}$ to estimate potential output and output gap in the United States. While as an unobservable variable, it is always a challenge to estimate potential output, the results of our multivariate (MV) filtering methodology are more robust than other available estimation techniques, such as singlevariate (SV) filters or hybrid approaches (described in section III). This is due to several factors: the MV filter's use of a host of information from the labor market and industrial capacity utilization; its use of economic relationships, such as the Phillips curve; and the fact that the MV filter allows for a non-deterministic trend for potential output. The MV filter is also flexible to include additional economic variables, as long as there is a theoretical (though reduced from) relationship between the underlying variable and one of the determinants of growth.

We estimate potential output, NAIRU, capacity utilization, and labor force participation, and calculate the gap between these estimates and actual data. We also show that our model is more robust than other common filtering techniques, in the sense that it corrects for the end-of-sample problem, which is a widely common problem.

The rest of the paper is organized as follows. In the next section, we provide the definition of potential output used in this paper. Section III briefly reviews the relevant exiting literature. Section IV describes our methodology, and the results are reported in section V. A discussion of end-of-sample performance of the model is presented in section VI. Section VII concludes.

\footnotetext{
${ }^{1}$ International Monetary Fund (2015), Chapter 3, has also employed the model from Blagrave and others (2015) to estimate potential output for a host of countries including the U.S.
} 


\section{Definitions}

In this paper, potential output is defined as the level of output that can be achieved without giving any upside or downside pressures on inflation. This definition is based on Okun (1962) and is widely used in the literature. The output gap is defined as the difference between the actual and potential output in percent of potential output. When the output gap is zero, there is no upward or downward pressure on inflation, as actual demand coincides with economy's potential. Shocks can affect actual output and potential output differently, leading to non-zero output gap levels. If the output gap is positive, so that actual output is greater than potential output, inflation will begin to rise in response to demand pressures. Similarly, if the output gap is negative, so that actual output falls below potential output, prices will begin to fall to reflect weak demand. An important feature of this paper is that, macroeconomic shocks are not exclusive to the actual output; potential can also be hit by shocks. In other words, the path of potential output is not deterministic. This is in contrast to many contributions in the literature, some of which we briefly review below.

\section{Existing Methodologies}

All commonly used methodologies to estimate the potential output involve filtering of the macroeconomic data to extract the unobservable underlying potential output level from cyclical variations in the output.

\section{Singlevariate and hybrid approaches}

The simplest methodology to estimate potential output is the singlevariate (SV) filter. This is a purely statistical methodology, which filters the actual GDP data to extract the trend as its estimate of potential output. The most common SV filter is the Hodrick-Prescott (HP) filter. It is very easy to use the HP filter because it only requires one data series (output). However, for the same reason, the HP filter is not a reliable technique for estimating potential: it does not take advantage of information from other economic data, say inflation or labor market indicators, to guide its estimate of potential output. There are other technical problems with the HP filter too, the most import of which is the end-of sample problem, with estimates towards the end of a given sample period being subject to significant revisions as more data ultimately become available and the sample is extended.

Another technique to estimate potential output is the "hybrid" approach. It uses a SV filter to estimate trend labor and total factor productivity (TFP) and combines them with capital stock through an assumed production function to arrive at potential output. The Congressional Budget Office (2001) provides a detailed account of such a hybrid model, in which the methodology is applied to different sectors of the U.S. economy. This approach is richer than a SV filter because it allows for more detailed examination of the drivers of potential. A downside of this approach is that it assumes capital is always at its potential. The hybrid approach also suffers from the endof-sample problems. In addition, neither the hybrid approach nor the SV filter necessarily produce estimates of potential, which are consistent with the definition of the level giving no pressure for inflation rise or fall as they fail to necessarily adjust for variations in inflation in their estimates. 
Both the SV filter and the hybrid approach also suffer from the potential misspecification by assuming a deterministic trend. In other words, trend potential output is not allowed to respond to shocks that could raise or lower potential over time. This is problematic, especially when the economy is hit by a large real shock such as during the GR.

MV filter

Many contributions have adopted MV filtering methodologies to estimate potential output. Some examples are models of Laxton and Tetlow (1992), Kuttner (1994), Benes and others (2010), Fleischman and Roberts (2011), and Blagrave and others (2015). MV filtering involves separating potential output from cyclical fluctuations, through the use of data and relationships between output and other macroeconomic variables, such as inflation, labor market indicators, capital formation indicators, etc. This approach adds economic structure to estimates by conditioning them on some basic theoretical relationships (such as a Phillip's curve relating the inflation process to the output gap). MV filtering methodologies are more complicated than SV filtering methodologies and require more data, but are at the same time more reliable because they use more information from the data for their estimates.

Shortcomings of the MV filtering approach are similar to those facing other methods - there remains an end-of-sample problem, (although we have addressed it largely in this paper using the information from growth and inflation expectations) and the estimates of potential and the output gap are only improved relative to a simple statistical filtration if the structural relationships specified in the filter are valid ones.

The MV filtering approach has the advantage of imposing well-known empirical relationships. In particular, the MV filtering approach adopted in this paper ensures that estimates of the output gap and potential are consistent with the Okun definition of potential. In addition, in its simplest form, this technique is relatively easy to implement requiring only a few variables, and it can also be augmented where data availability permits.

\section{DSGE models}

Some contributions have used DSGE models to estimate potential and the output gap (see, for example, Vetlov and others, 2011). These models have more tangible micro foundations and are very appealing. Nonetheless, these they are not so easy to interpret and remain a challenge for policymakers to use in formulation of policies.

\section{Other models}

While most contributions, including this paper, have a closed-economy model, some recent work has focused on an open economy case. For example, Alberoa and others (2013) have expanded the definition of potential output to include global imbalances. Yet, another recent strand of literature is focusing on including financial imbalances in the definition of the potential output (see Borio, Disyatat, and Juselius (2013)). 


\section{Methodology}

The MV filtering approach specified in this paper is an extension of Blagrave and others (2015). In addition to real GDP growth, core PCE inflation, and the unemployment rate, we introduce new blocks to introduce capacity utilization and labor market participation rate in the model.

Inclusion of capacity utilization is crucial to have a reliable measure of potential output. ${ }^{2}$ Figure 2 shows that in the second half of 1990s, capacity utilization and the unemployment rate were both declining, with opposite implications for potential growth. ${ }^{3}$ Hence, just relying on labor market data could be misleading for projecting potential. The decline in the unemployment rate is consistent with an improving potential output growth, while a decline in the capacity utilization likely leads to lower potential output growth. Ignoring the capacity utilization and only relying on the unemployment rate, therefore, results in overestimating potential output and underestimating the path of the output gap, in the later years.

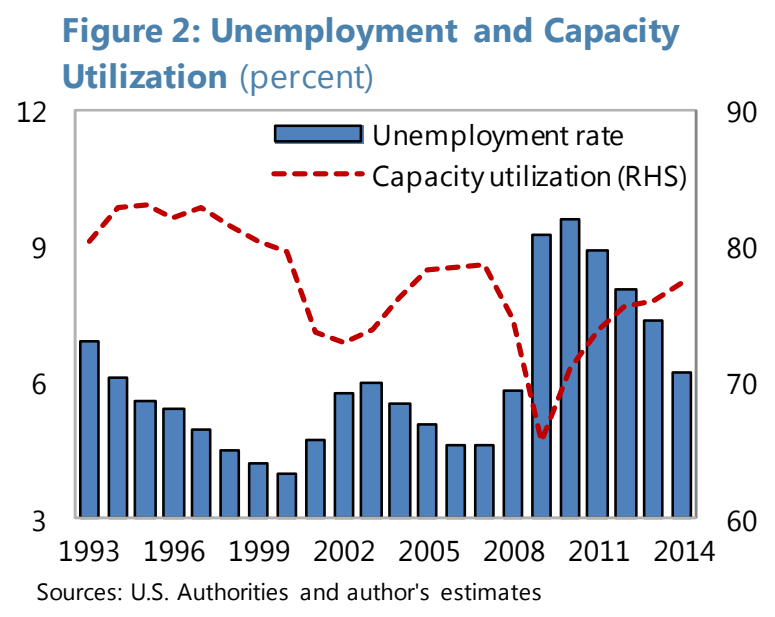

We specify reduced-formed relationships between these observable variables and some latent variables that we introduce in the model.

\footnotetext{
${ }^{2}$ The new block on labor force participation rate also enriches the model, but we do not see it as crucial as the block on capacity utilization. This is because the original model already included another labor market block (on unemployment rate.)

${ }^{3}$ Analyzing why capacity utilization has been declining since 1990 is beyond the scope of this paper.
} 


\section{Model}

The output gap is defined as the deviation of real GDP, in log terms $(Y)$, from its potential level $(\bar{Y})$ :

$$
y=Y-\bar{Y}
$$

The stochastic process for output (real GDP) is comprised of three equations, and subject to three types of shocks. First, the level of potential output $\left(\bar{Y}_{t}\right)$ evolves according to potential growth $\left(G_{t}\right)$ and a level-shock term $\left(\varepsilon_{t}^{\bar{Y}}\right)$ :

$$
\bar{Y}_{t}=\bar{Y}_{t-1}+G_{t}+\varepsilon_{t}^{\bar{Y}}
$$

Potential growth is also subject to shocks $\left(\varepsilon_{t}^{G}\right)$, with their impact fading gradually according to the parameter $\theta$ (with lower values entailing a slower adjustment back to the steady-state growth rate following a shock):

$$
G_{t}=\theta G^{S S}+(1-\theta) G_{t-1}+\varepsilon_{t}^{G}
$$

Finally, the output gap closes over time at a speed pinned down by parameter $(\phi)$, but is also subject to demand shocks $\left(\varepsilon_{t}^{y}\right)$ :

$$
y_{t}=\phi y_{t-1}+\varepsilon_{t}^{y}
$$

In the absence of any shocks, output would be at its steady state path and the output gap would be zero. Shocks can be threefold. They occur to: the level of potential $\left(\varepsilon_{t}^{\bar{Y}}\right)$; the growth rate of potential $\left(\varepsilon_{t}^{G}\right)$; or the output gap $\left(\varepsilon_{t}^{y}\right)$, and can cause output to deviate from this initial steadystate path over time. Output is assumed to always return to its steady-state path following any shocks. A shock to the level of potential output in any given period will cause output to be permanently higher (or lower) than its initial steady-state path. Similarly, shocks to the growth rate of potential can cause the growth rate of output to be temporarily higher, before ultimately slowing back to the steady-state growth rate (note that this would still entail a higher level of output). And, finally, shocks to the output gap cause only a temporary deviation of output from potential.

In order to identify the three aforementioned output shock terms, a Phillips curve equation for inflation is added, which links the evolution of the output gap (an unobservable variable) to observable data on inflation according to the process. The Phillips curve equation is as follows: ${ }^{4}$

$$
\pi_{t}=\lambda \pi_{t+1}+(1-\lambda) \pi_{t-1}+\beta \frac{y_{t}}{5-y_{t}}+\varepsilon_{t}^{\pi}
$$

\footnotetext{
${ }^{4}$ This non-linear form is only used for projections. For historical Bayesian estimation, a linear equation ( $\left.\pi_{t}=\lambda \pi_{t+1}+(1-\lambda) \pi_{t-1}+\beta y_{t}+\varepsilon_{t}^{\pi}\right)$ has been used, given that we do not have at our disposal a non-linear estimation technique. The nonlinearity does not make a notable difference in the results, unless the output gap is large and positive.
} 
Equations describing the evolution of unemployment are further included to provide additional identifying information for the estimation of the output gap. The first three of these equations (6$8)$ are similar to the equations presented above for output. The unemployment gap $\left(u_{t}\right)$ is defined in equation 6 , as the difference between the actual unemployment rate $\left(U_{t}\right)$ and NAIRU $\left(\bar{U}_{t}\right)$ :

$$
u_{t}=\bar{U}_{t}-U_{t}
$$

NAIRU converges to its steady state level $\left(\bar{U}^{S S}\right)$, which is determined outside the model, but also has a time varying trend $\left(U G_{t}\right)$ and can experience shocks as well $\left(\varepsilon_{t}^{\bar{U}}\right)$ :

$$
\bar{U}_{t}=\tau_{4} \bar{U}^{S S}+\left(1-\tau_{4}\right) \bar{U}_{t-1}+\overline{U G}_{t}+\varepsilon_{t}^{\bar{U}}
$$

The time varying portion of NAIRU, reflects gradually increased dynamism over time, due to improved information sharing and easier mobility of the labor force, but could experience shocks $\left(\varepsilon_{t}^{\overline{U G}}\right)$ :

$$
\overline{U G}_{t}=\tau_{3} \overline{U G}_{t-1}+\varepsilon_{t}^{\overline{U G}}
$$

The last equation of the labor market block is an Okun's rule equation, in which the unemployment gap depends on its past value and the output gap, but it also can experience $\operatorname{shocks}\left(\varepsilon_{t}^{u}\right)$ :

$$
u_{t}=\tau_{1} u_{t-1}+\tau_{2} y_{t}+\varepsilon_{t}^{u}
$$

One important aspect of the U.S. labor market is the effect of aging on labor participation and hence the unemployment rate. The following set of equations is intended to capture this important dynamic. Equation 10 defines the labor force participation gap as the difference between labor force participation $\left(L P_{t}\right)$ and potential labor force participation $\left(\overline{L P}_{t}\right)$ :

$$
l p_{-} g a p_{t}=L P_{t}-\overline{L P}_{t}
$$

Potential labor force participation converges to its steady state $\left(\overline{L P}^{S S}\right)$, absent any shocks $\left(\varepsilon_{t}^{\overline{L P}}\right)$ :

$$
\overline{L P}_{t}=\vartheta_{3} \overline{L P}^{S S}+\left(1-\vartheta_{3}\right) \overline{L P}_{t-1}+\varepsilon_{t}^{\overline{L P}}
$$

Labor force participation gap depends on its lagged value and the unemployment gap, but can also experience shocks $\left(\varepsilon_{t}^{l p \_g a p}\right)$ :

$$
l p_{\_} g a p_{t}=\vartheta_{1} l p_{-} g a p_{t-1}+\vartheta_{2} u_{t}+\varepsilon_{t}^{l p_{-} g a p}
$$

Next, equations describing the evolution of capacity utilization provide further identifying information. In equation 13, capacity utilization gap $\left(\right.$ capu_gap $\left._{t}\right)$ is defined as the difference of capacity utilization $\left(C A P U_{t}\right)$ and its potential level $\left(\overline{C A P U}_{t}\right)$ at each period:

$$
\text { capu_gap }_{t}=C A P U_{t}-\overline{C A P U}_{t}
$$


Potential capacity utilization converges to its steady state level $\left(\overline{C A P U}^{S S}\right)$ over time, but could also experience shocks:

$$
\overline{C A P U}_{t}=\aleph_{3} \overline{C A P U}^{S S}+\left(1-\aleph_{3}\right) \overline{C A P U}_{t-1}+\varepsilon_{t}^{\overline{C A P U}}
$$

The last equation for the capacity utilization block is in the spirit of an Okun's rule, but for capacity utilization. Capacity utilization gap depends on its lag, the output gap, but it can also experience shocks $\left(\varepsilon_{t}^{\text {capu_gap }}\right)$ :

$$
c a p \__{-} g a p_{t}=\aleph_{1} c a p u_{-} g a p_{t-1}+\aleph_{2} y_{t}+\varepsilon_{t}^{c a p u \_g a p}
$$

Next, we add equations that enable us to use information from growth and inflation expectations data. These equations capture the assumptions that expectations are formed rationally and fulfilled in the longer term, but do not materialize exactly in the short term, modeled with shocks:

$$
\begin{aligned}
& g_{t+j}^{E}=g_{t+j}+\varepsilon_{t+j}^{g^{E}}, \mathrm{j}=0, \ldots, 5 \\
& \pi_{t+j}^{E}=\pi_{t+j}+\varepsilon_{t+j}^{\pi^{E}}, \mathrm{j}=0,1
\end{aligned}
$$

Where $\left(g_{t+j}^{E}\right)$ and $\left(g_{t+j}\right)$ are expected and actual model-consistent GDP growth rates in j periods ahead, respectively. The difference between the two is captured by a shock term $\left(\varepsilon_{t+j}^{g^{E}}\right)$. Likewise, $\left(\pi_{t+j}^{E}\right)$ and $\left(\pi_{t+j}\right)$ are expected and actual model-consistent core PCE inflation rates in $\mathrm{j}$ periods ahead, respectively. The difference between the two is captured by a shock term $\left(\varepsilon_{t+j}^{\pi^{E}}\right)$.

Data for growth and inflation expectation are from Consensus Economics. The 'strength' of the relationship between the data on consensus and the model's forward expectations is determined by the standard deviation of the error terms. In practice, the estimated variance of these terms allows consensus data to influence, but not completely override, the model's expectations, particularly at the end of the sample period. The incorporation of consensus forecasts can be thought as a heuristic approach to blend forecasts from different sources and methods. The resulting impact of this information on the historical estimates of potential and the output gap is modest, as shown in the following section.

We use annual data for observables (GDP, PCE inflation, unemployment rate, labor force participation, and capacity utilization) from the U.S. authorities and other variables in the model are unobservable. We estimate the model with Bayesian estimation techniques. This is what is generally referred to as Kalman filtering techniques. ${ }^{5}$

\footnotetext{
${ }^{5}$ See Hamilton (1994) for a more detailed discussion of the Kalman filter, which is used to obtain estimates of the unobservable variables as part of the estimation process.
} 
To put it briefly, we apply a Bayesian Maximum Likelihood technique, in which priors are chosen for all the parameters of the model and the shocks. A truncated normal distribution for each parameter is assumed as follows

$$
\left(\overline{\theta_{i}}, \frac{1}{p} \sigma_{\bar{\theta}_{i}}^{2}\right)
$$

The following optimization problem is solved to find posteriors of the parameters:

$$
\max _{\theta} \log L(\theta ; Y)-p \sum_{i} \frac{\left(\theta_{i}-\overline{\theta_{i}}\right)}{\sigma_{\overline{\theta_{i}}}^{2}}
$$




\section{Results}

Figure 3 shows the path of real GDP growth and potential real GDP growth. In the second half of $1990 \mathrm{~s}$, potential growth reached about $3 \frac{1}{2}$ percent, but since early $2000 \mathrm{~s}$, it started falling. The global financial crisis brought activity to a halt and brought potential output growth to the negative territory. Potential growth started to pick up in 2010, and is currently estimated at around its steady state growth rate of about 2.0 percent. Potential growth is expected to surpass its steady state value in the next 2-3 years, as the recovery is expected to gain momentum and investment is expected to pickup. In the medium term, however, structural changes in the economy related to population again will slow potential growth and bring it back to its steady state value of 2.0 percent.

Estimates show that Nairu and potential capacity utilization also followed a similar path. Nairu reached about 8 percent after the global financial crisis, but

Figure 3: Growth and Potential Growth

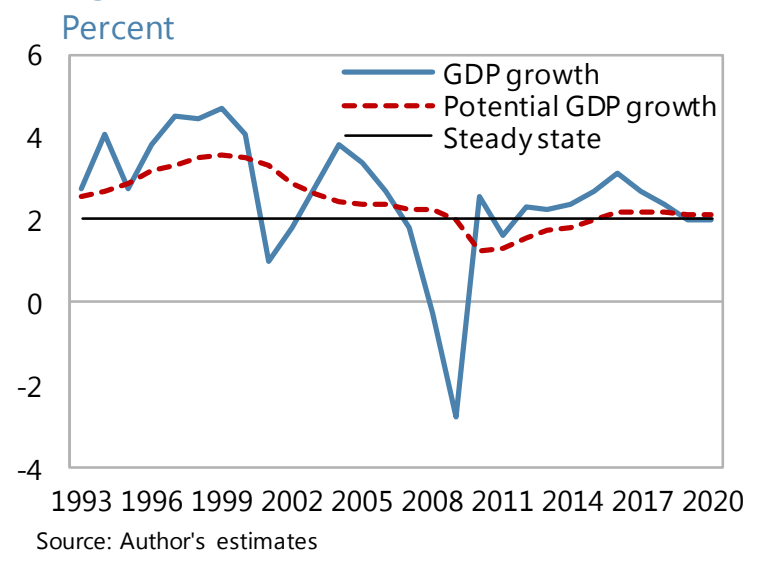
has since decreased to around 6 percent, which is about one percentage point about its steady state level. Likewise, potential capacity utilization collapsed to below 70 percent after the global financial crisis, but has now recovered to the pre-crisis levels of around 78 percent.

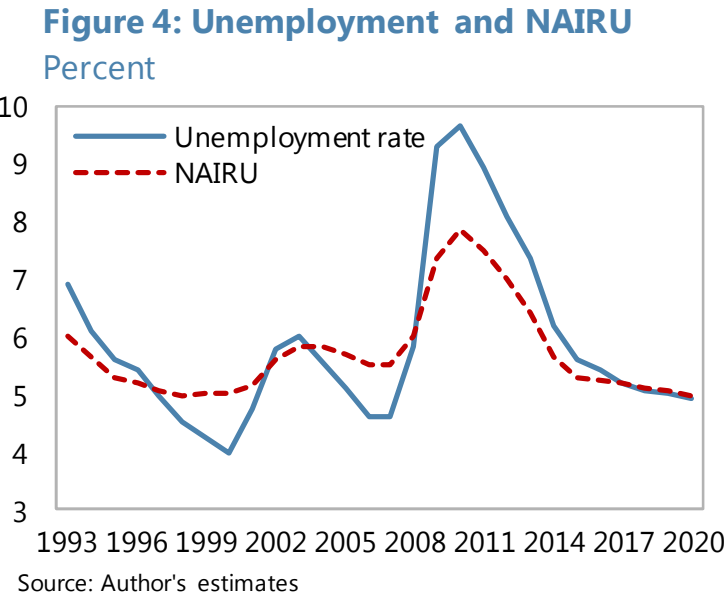

While potential growth is estimated to be around its steady state level, potential output is yet to catch up to its steady state level. Figure 6 shows that by end-2014, the output gap stood at around -2.0 percent, having recovered significantly from the low level of $-5 \frac{1}{4}$ in 2009 . It is projected that the output gap would continue shrinking to close in 2017.

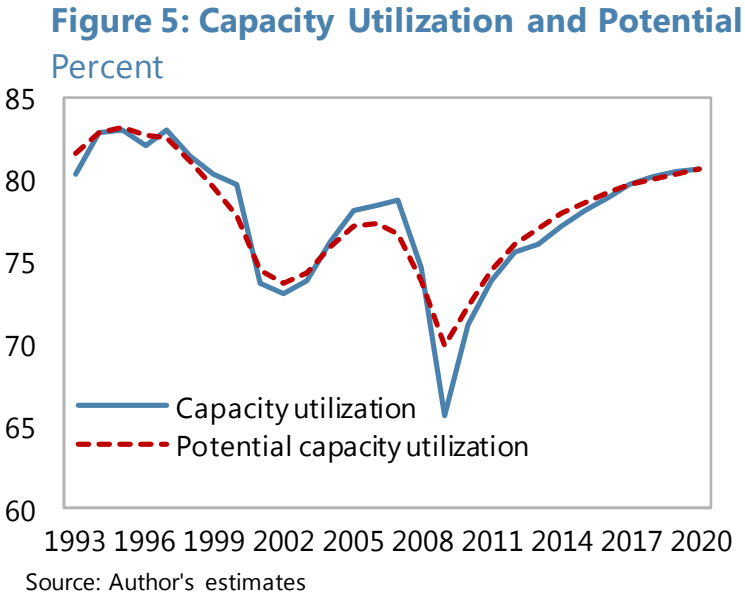

Figure 6: Output, Unemployment, and

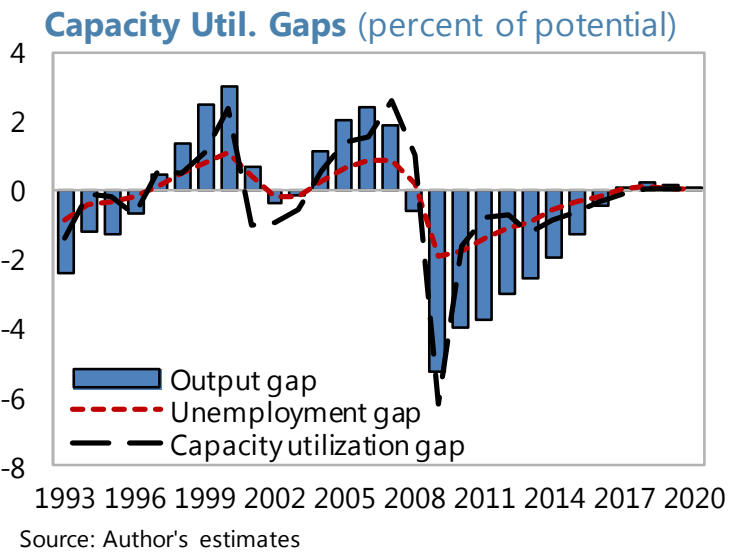




\section{Dealing With the End-Of-SAMPle Problem}

A well known problem with filters is the end-of-sample problem. Recall that the optimization problem that, say, an HP filter solves is through trading off the size of deviations from trend and the smoothness of that trend. Consider a postive temporary shock to output. This would not result in a sizable change in the trend since this implies raising the trend before the shock and lowering it afterwards. At the end of the sample, however, there is no penalty, implying that the optimal trend will be more responsive to temporary shocks at the end of sample than in middle of the sample. MV filters are also generally subject to this end-ofsample problem. However, in our MV filter, this issue has been largely resolved through using information from growth and inflation expectations. Figures 7-9 show estimates of potential growth and output gap, using our MV filter, as well as the HP filter. First we note from Figure 7 that estimates of output gap are very different under the MV and HP filters. ${ }^{6}$ This is not surprising because even the definition potential output under the two methodologies is different. Potential output in the HP filter is simply trend output, whereas potential output from the MV filter is defined as the level consistent with no upside or downside inflation pressures.

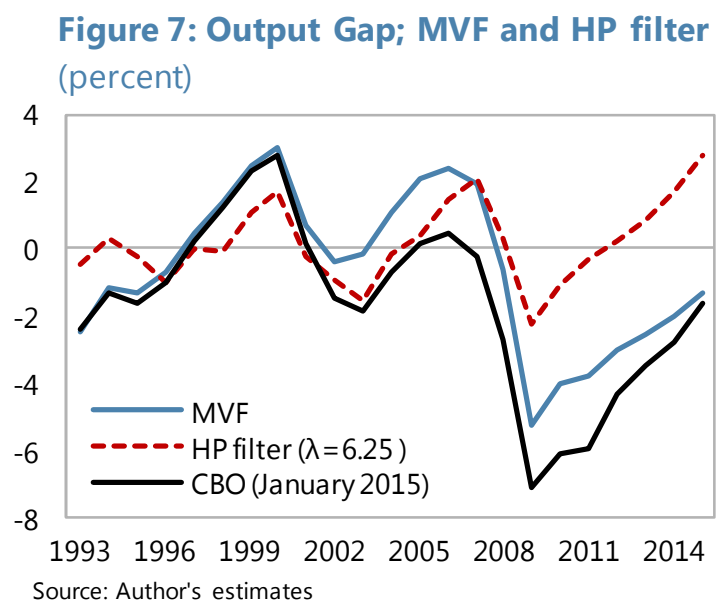

The end-of-sample problem could be seen in Figures 8-9. In each of these figures, potential output is projected for 5 periods ahead and with each additional year, the sample is extended by one year and potential output is reestimated. Out-of-sample estimates from the MV filter remain much closer to the final (current) estimate, which is shown in black, much more so than similar results for the HP filter.

\footnotetext{
${ }^{6}$ We have also included projections of Congressional Budget Office (CBO) for readers' information. CBO uses a hybrid approach, as mentioned in Section III.
} 


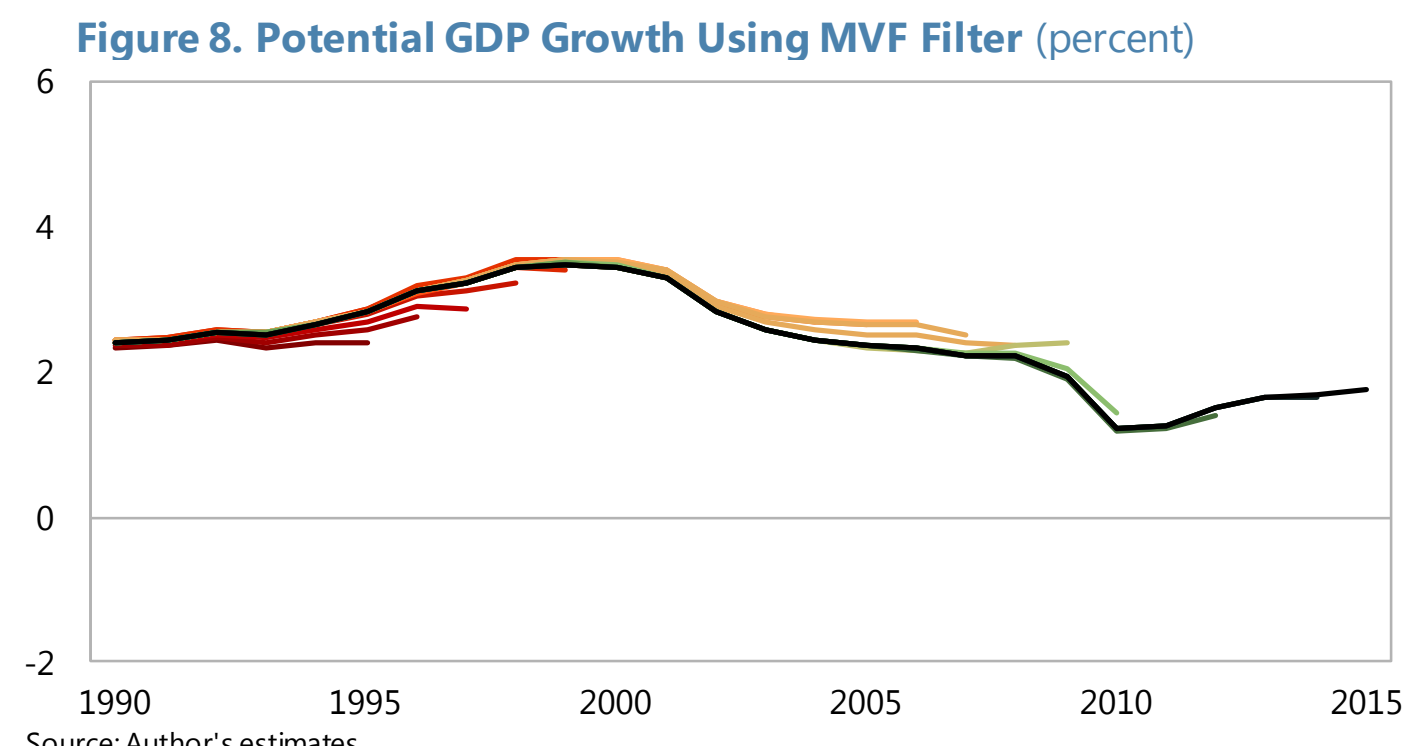

Source: Author's estimates

Figure 9. Potential GDP Growth Using HP Filter; $\lambda=6.25$ (percent)

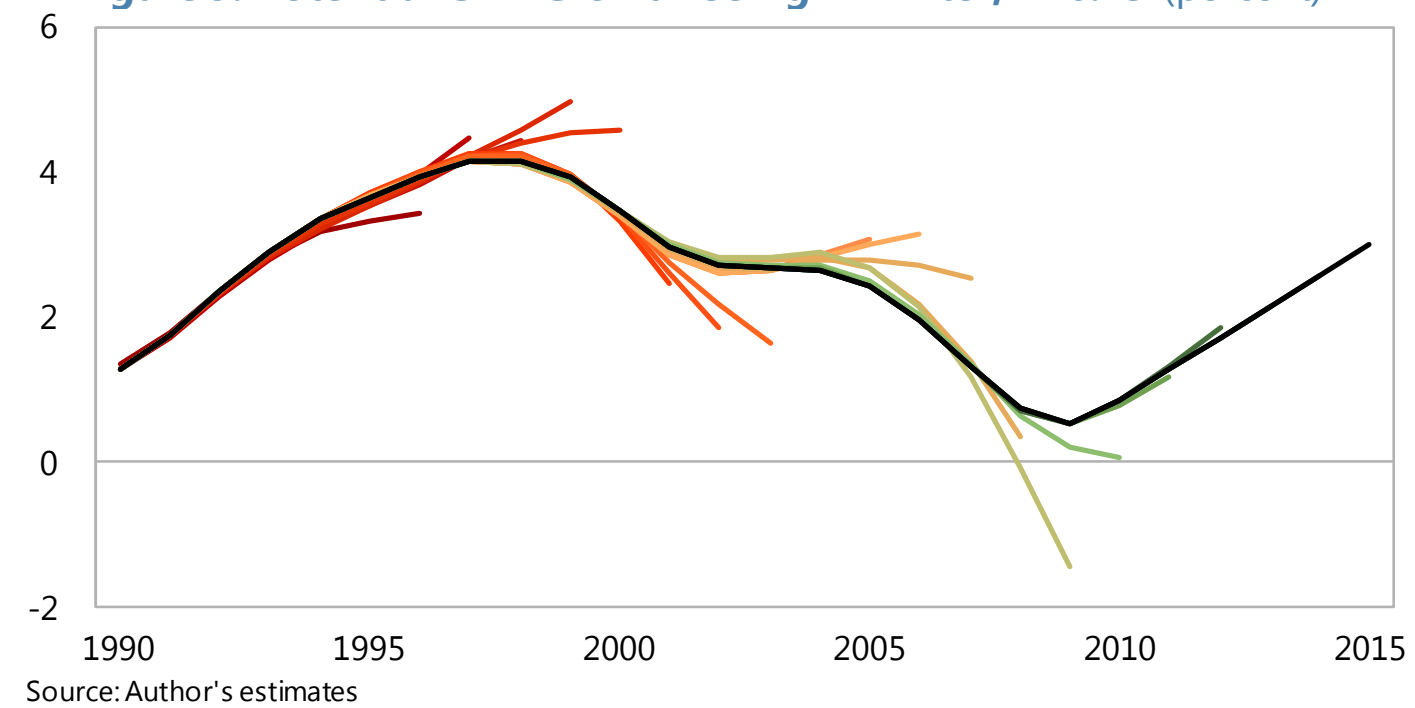

VII. ConClusion

This paper has adapted the methodology developed by Blagrave and others (2015) to the U.S. economy. The methodology used is a combination of filtering techniques, use of reduced form economic relationships, and use of survey data on growth and inflation expectations. The results are shown to be more robust than simple SV filtering techniques, as the end-of-sample problems have been largely tackled in the MV filtering model used. However, there still remain large uncertainties around the results as potential output is unobservable.

Future work could focus on introducing global and financial imbalances into this MV filtering model, because large and persistent imbalances indeed imply that a closed-economy model could provide gravely incorrect paths of potential output. 


\section{References}

Aguiar, M., and G. Gopinath, 2007, "Emerging Market Business Cycles: The Cycle Is the Trend”, Journal of Political Economy, University of Chicago Press, vol. 115, pp. 69-102

Alberoa, E., A. Estrada, and D. Santabarbara, 2013, "Growth Beyond Imbalances. Sustainable Growth Rates and Output Gap Reassessment," Banco de Espana Documentos de Trabajo no. 1313

Bank of Canada, 2009, Monetary Policy Report, July 2009. http://www.bankofcanada.ca/wp-content/uploads/2010/04/mpr230709.pdf

Bank of Canada, 2014, Monetary Policy Report, October 2014. http://www.bankofcanada.ca/wp-content/uploads/2014/07/mpr-2014-10-22.pdf

Barnett, R., S. Kozicki, and C. Petrinec, 2009, "Parsing Shocks: Real-Time Revisions to Gap and Growth Projections for Canada," Federal Reserve Bank of St. Louis Review, pp. 247265.

Benes, J., K. Clinton, R. Garcia-Saltos, M. Johnson, D. Laxton, P. Manchev, and T. Matheson, 2010, "Estimating Potential Output with a Multivariate Filter," IMF Working Paper WP/10/285.

Benes, J., M. Kumhof, and D. Laxton. 2014, "Financial Crises in DSGE Models: Selected Applications of MAPMOD.” Working Paper 14/56, International Monetary Fund, Washington.

Benes, J., M. Kumhof, and D. Laxton. 2014, "Financial Crises in DSGE Models: A Prototype Model.” Working Paper 14/57, International Monetary Fund, Washington.

Benes, J., and P. N'Diaye, 2004, “A Multivariate Filter for Measuring Potential Output and the NAIRU: Application to The Czech Republic," IMF Working Paper WP/04/45.

Blagrave, P., R. Garcia-Saltos, D. Laxton, and F. Zhang, “A Simple Multivariate Filter for Estimating Potential Output," IMF Working Paper WP/15/79.

Borio, C., P. Disyatat, and M. Juselius, 2013, "Rethinking Potential Output: Embedding Information about the Financial Cycle," BIS Working paper no. 404.

Butler, L., 1996, “The Bank of Canada's New Quarterly Projection Model, Part 4. A SemiStructural Method to Estimate Potential Output: Combining Economic Theory with a Time-Series Filter," Technical Report no. 77 (Ottawa: Bank of Canada).

Cotis, JP, J. Elmeskov, and A. Mourougane, 2004, "Estimates of Potential Output: Benefits and Pitfalls from a Policy Perspective." Published in Euro Area Business Cycle: Stylized Facts and Measurement Issues, pp. 35-60. 
D’Auria, F, C. Denis, K. Havik, K. McMorrow, C. Planas, R. Raciborski, W. Roger, A. Rossi, 2010, "The production function methodology for calculating potential growth rates and output gaps" European Commission Economic Papers No 420, July 2010.

De Masi, P. R., 1997, “IMF Estimates of Potential Output: Theory and Practice,” IMF Working Paper WP/97/177.

Fleischman, C., and J. M. Roberts, 2011, "From Many Series, One Cycle: Improved Estimates of the Business Cycle from a Multivariate Unobserved Components Model," Finance and Economics Discussion Series 2011-46, Federal Reserve Board.

Giorno, C, P. Richardson, D. Roseveare, and P. van den Noord, 1995, "Estimating Potential Output, Output Gaps and Structural Budget Balances,” OECD Working Paper no. 152.

Hamilton, J, 1994. Time Series Analysis, Princeton University Press, New Jersey.

Hodrick, R.J., and E.C. Prescott, 1997, "Post-War U.S. Business Cycles: An Empirical Investigation," Journal of Money, Credit and Banking, Vol. 29(1), pp. 1-16.

Kuttner, K. N., 1994, "Estimating Potential Output as a Latent Variable" Journal of Business and Economic Statistics, Vol. 12, pp. 361-68.

Laxton, D., and R. Tetlow, 1992, “A Simple Multivariate Filter for the Measurement of Potential Output,” Technical Report no. 59 (Ottawa: Bank of Canada).

Mishkin, F.S., 2007, “Inflation Dynamics,” Annual Macro Conference, Federal Reserve Bank of San Francisco, March. http://www.federalreserve.gov/newsevents/speech/Mishkin20070323a.htm

Okun, A.M., 1962, "Potential GNP: Its Measurement and Significance," in Proceedings of the Business and Economic Statistics Section, pp. 98-104 (Washington: American Statistical Association).

Prachowny, M., 1993, “Okun's Law: Theoretical Foundations and Revised Estimates,” The Review of Economics and Statistics, Vol. 75, No. 2, pp. 331-336.

The Congressional Budget Office, 2001, CBO’s Method for Estimating Potential Output

Vetlov, I., T. Hledik, M. Jonsson, H. Kucsera, and M. Pisani, 2011. "Potential Output in DSGE Models,” ECB Working Paper Series No. 1351.

Zmitrowicz, K, and M. Khan, 2014, "Beyond the Unemployment Rate: Assessing Canadian and US Labour Markets Since the Great Recession.” Bank of Canada Review, Spring 2014

International Monetary Fund (2015), "Where Are We Headed? Perspectives on Potential Output," World Economic Outlook, April 2015, Chapter 3. 
APPENDIX I: ESTIMATION RESULTS

\begin{tabular}{|c|cc|cc|cc|}
\hline \multicolumn{3}{|c|}{ Regularized Maximum Likelihood Estimation Results } \\
\hline & \multicolumn{2}{|c|}{ Mode } & \multicolumn{2}{c|}{ Support } & \multicolumn{2}{c|}{ Dispersion } \\
& Prior & Posterior & Prior & Posterior & Prior & Posterior \\
\hline$\theta$ & 0.100 & 0.097 & 0.050 & 0.990 & 0.100 & 0.103 \\
$\Phi$ & 0.800 & 0.786 & 0.100 & 0.990 & 0.100 & 4.000 \\
$\lambda$ & 0.250 & 0.172 & 0.050 & 0.990 & 0.100 & 4.000 \\
$\beta$ & 0.200 & 0.213 & 0.050 & 3.000 & 0.100 & 4.000 \\
$\tau_{1}$ & 0.330 & 0.569 & 0.050 & 0.990 & 0.010 & 0.040 \\
$\tau_{2}$ & 0.200 & 0.317 & 0.050 & 0.990 & 0.010 & 0.096 \\
$\tau_{3}$ & 0.900 & 0.903 & 0.050 & 0.990 & 0.010 & 4.000 \\
$\tau_{4}$ & 0.100 & 0.126 & 0.050 & 0.990 & 0.010 & 4.000 \\
$\vartheta_{1}$ & 0.700 & 0.700 & 0.005 & 1.900 & 0.010 & 0.010 \\
$\vartheta_{2}$ & 0.300 & 0.282 & 0.050 & 2.000 & 0.010 & 0.010 \\
$\vartheta_{3}$ & 0.050 & 0.030 & 0.030 & 0.900 & 0.050 & 0.024 \\
$\kappa_{1}$ & 0.700 & 0.376 & 0.005 & 2.000 & 0.100 & 0.057 \\
$\kappa_{2}$ & 0.300 & 0.655 & 0.050 & 2.000 & 0.100 & 4.000 \\
$\kappa_{3}$ & 0.200 & 0.226 & 0.050 & 0.990 & 0.010 & 4.000 \\
\hline
\end{tabular}

\section{Appendix II: Labor Force Participation Projections}

Figure 10 shows the path of estimated potential and actual labor force participation. It is well known that because of demographics, labor force participation has been trending down since mid 1990s. Model results show that, as a result the GR, labor force participation dipped to below its potential level. The model predicts a flat path for actual labor force participation rate through the medium term, while potential labor force participation is still expected to decline and converge to the actual level at current levels.

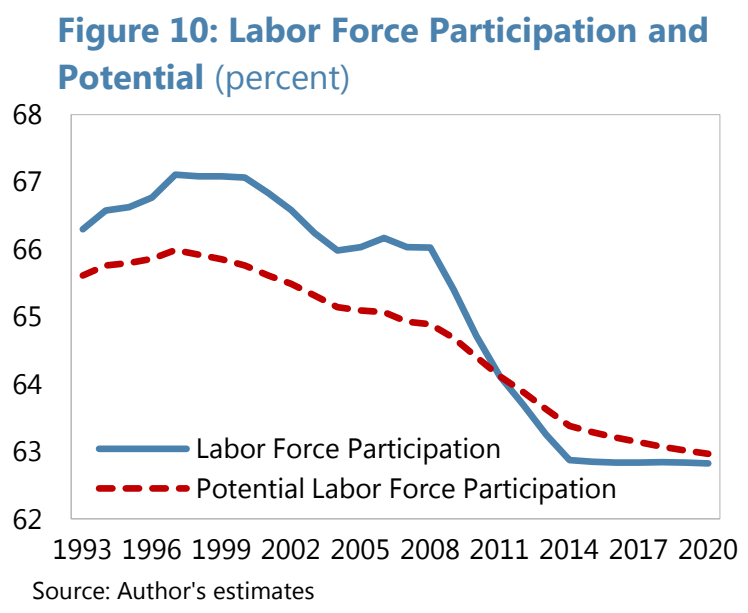

